\title{
In vitro antibacterial effects of Tanreqing injection combined with vancomycin or linezolid against methicillin-resistant Staphylococcus aureus
}

Weifeng Yang ${ }^{1 \dagger}$, Jueling Liu ${ }^{1 \dagger}$, Biljana Blažeković, Yanan Sun ${ }^{1}$, Shuhua Ma ${ }^{1}$, Chuanyun Ren ${ }^{3}$, Sanda Vladimir-Knežević ${ }^{2}$, Chaohua Li ${ }^{1}$, Yajun Xing ${ }^{1}$, Guijie Tian $^{4}$ and Yi Wang ${ }^{1 *}$

\begin{abstract}
Background: Combining conventional drugs and traditional medicine may represent a useful approach to combating antibiotic resistance, which has become a serious threat to global public health. This study aimed to evaluate the potential synergistic interactions between Tanreging (TRQ) injection, a commercial traditional Chinese medicine formula used for the treatment of upper respiratory tract infection, and selected antibiotics used against methicillin-resistant Staphylococcus aureus (MRSA).

Methods: The minimum inhibitory concentrations (MICs) of TRQ, vancomycin and linezolid against planktonic MRSA strain were determined by the broth microdilution method. The combined effects of TRQ and antibiotics were studied by the checkerboard method and the time-kill curve assay. The 2,3-bis-(2-methoxy-4-nitro-5-sulfophenyl)-2H-tetrazolium5-carboxanilide (XTT) reduction assay was employed to determine the inhibitory effect of the test compounds alone and in combination against MRSA embedded in biofilms.

Results: MRSA strain was found to be susceptible to TRQ formula with MIC value $4125 \mu \mathrm{g} / \mathrm{ml}$, while the MIC values for antibiotics, vancomycin and linezolid, were $2.5 \mathrm{\mu g} / \mathrm{ml}$. The checkerboard analysis revealed that TRQ markedly enhanced activities of the tested antibiotics by reducing their MICs. In the time-kill analysis, TRQ at $1 / 2 \times M I C$ in combination with vancomycin at 1/2 $\times \mathrm{MIC}$, as well as TRQ at $1 / 8 \times \mathrm{MIC}$ in combination with linezolid at $1 / 2 \times \mathrm{MIC}$ decreased the viable colonies by $\geq 2 \log 10 \mathrm{CFU} / \mathrm{ml}$, resulting in a potent synergistic effect against planktonic MRSA. In contrast to the tested antibiotics, which did not affect mature MRSA biofilms at subinhibitory concentrations, TRQ alone showed strong ability to disrupt preformed biofilms and induce biofilm cell death. The combination of TRQ with vancomycin or linezolid at sub-MIC concentrations resulted in a synergistic antibiofilm effect significantly higher than for each single agent.

Conclusions: This study provides the first in vitro evidence on the synergistic effects of TRQ and vancomycin or linezolid against planktonic and biofilm MRSA, and revealed their optimal combination doses, thereby providing a rational basis for the combination therapies against MRSA.
\end{abstract}

Keywords: Tanreqing, Vancomycin, Linezolid, Methicillin-resistant Staphylococcus aureus, MRSA, Synergistic effect, Biofilm

\footnotetext{
* Correspondence: prof.wangyi@foxmail.com

${ }^{+}$Wei Feng Yang and Jue Ling Liu contributed equally to this work.

${ }^{1}$ Experimental Research Center, China Academy of Chinese Medical Sciences,

Nanxiao Road 16, Dongzhimen, Beijing 100700, People's Republic of China

Full list of author information is available at the end of the article
}

(c) The Author(s). 2018 Open Access This article is distributed under the terms of the Creative Commons Attribution 4.0 International License (http://creativecommons.org/licenses/by/4.0/), which permits unrestricted use, distribution, and reproduction in any medium, provided you give appropriate credit to the original author(s) and the source, provide a link to the Creative Commons license, and indicate if changes were made. The Creative Commons Public Domain Dedication waiver (http://creativecommons.org/publicdomain/zero/1.0/) applies to the data made available in this article, unless otherwise stated. 


\section{Background}

Antimicrobial resistance is recognized today as a major global public health concern that threatens the effective prevention and treatment of many infectious diseases representing an ever-increasing health and economic burden [1]. Methicillin-resistant Staphylococcus aureus (MRSA) is one of the most important pathogenic bacteria causing nosocomial and community acquired infections. MRSA infections constitute today a serious and still evolving public health challenge worldwide due to their high incidence and associated increased morbidity, the risk of mortality and medical costs [2-4]. As MRSA is resistant to methicillin and related $\beta$-lactams, the glycopeptide antibiotic vancomycin has long been the drug of choice for most MRSA infections. However, its widespread use resulted in reduced MRSA susceptibility as well as the emergence of a vancomycin-resistant strain of $S$. aureus $[5,6]$. Several studies suggest that vancomycin may be less effective against serious MRSA infections with minimum inhibitory concentration (MIC) values at the higher end of the susceptibility and also associated the MIC increase with a substantial risk of vancomycin treatment failure and a higher mortality rate [7]. In addition, vancomycin-induced nephrotoxicity is an important adverse effect that can occur in patients following conventional and high doses of the drug [5, 8]. Linezolid is a newer antibacterial agent of the oxazolidinone class, which has a broad-spectrum of activity against the majority of common Gram-positive cocci. It has been found to be very useful for the treatment of MRSA infections where vancomycin has failed, but concerns about safety often limit its use. Also, the clinical reports have revealed the occurrence of linezolid resistant MRSA [6, 9]. Faced with the emergence of resistance to the last-resort antibiotics, their undesirable side effects, and general lack of new antibiotics, combination therapy has become an important new treatment strategy for MRSA infections. Additive and synergistic drug interactions can result in enhanced efficacy, delayed or reduced resistance, or minimized drug toxicity and side effects in patients.

Traditional Chinese medicine (TCM) has long been used in the Chinese population to treat various infectious diseases, and many prescriptions have been proved to be therapeutically effective $[10,11]$. The Tanreqing (TRQ) injection is a Chinese herbal preparation made from Scutellariae radix (Huang Qin), Lonicerae flos (Jin Yin Hua), Forsythiae fructus (Lian Qiao), Ursi fel (Xiong Dan) and Naemorhedi cornu (Shan Yang Jiao). Recent phytochemical studies have revealed the characteristic chemical complexity of this TCM formulation. More than 50 different constituents belonging to the classes of flavonoids, phenolic acids, cholic acids and amino acids have been identified in the TRQ injection. Among these, five active ingredients (baicalin, ursodeoxycholic acid, chenodeoxycholic acid, chlorogenic acid, and caffeic acid) are selected as chemical markers for its quality control [12]. According to the TCM theory, TRQ formula clears heat, detoxifies and removes phlegm and it has been used in China to treat respiratory tract infections, pneumonia and chronic obstructive pulmonary disease [13]. In the clinical practice TRQ injection is usually administered intravenously, although it can also be given by nebulisation [14]. Due to the complexity of this multi-component mixture, its metabolism and the molecular mechanisms of activity are still poorly understood. No clinical pharmacokinetic data are available for the TRQ injection. The few published preclinical studies suggest rapid distribution of its major constituents from plasma to tissues and the organs, thus favoring the drug efficacy [15-17].

Clinical data demonstrated that TRQ is safe and well tolerated, and it effectively treats respiratory infections [18-20], by improving vancomycin efficacy in patients with MRSA pneumonia [21, 22]. However, in vitro studies on the antibacterial activity of this standardized formula are still scarce. Our recent study demonstrated that TRQ inhibits the growth of planktonic Staphylococcus aureus as well as bacterial cells embedded in a biofilm. [23]. Based on the previous findings, this study aimed to evaluate in vitro antibacterial activity of TRQ and its possible synergistic interactions with conventional antibiotics against MRSA in order to provide useful evidence for the rational and improved MRSA treatment.

\section{Methods}

Antimicrobial agents and chemicals

Tanreqing injection (TRQ, $33 \mathrm{mg} / \mathrm{mL}$, lot no. Z20030054) was obtained from Shanhai Kaibao Pharmaceutical, China, vancomycin hydrochloride injection (lot no. 657) from Eli Lilly, Japan, and linezolid injection (lot no. 14K03U03) was from Pfizer, Norway. Tryptone and yeast extract were obtained from Oxoid, UK, $\mathrm{NaCl}$ from Merck, Germany, and 2,3,5-triphenyltetrazolium chloride (TTC) from Amresco, USA. 2,3-bis-(2-methoxy-4-nitro-5-sulfophenyl)-2H-tetrazolium-5-carboxanilide (XTT) and phenazine methosulfate (PMS) were purchased from Sigma-Aldrich, USA.

\section{Bacterial strain and growth conditions}

Methicillin-resistant Staphylococcus aureus (MRSA, ATCC 43300) was purchased from the American Type Culture Collection (ATCC, USA) and maintained in cryogenic storage at $-80{ }^{\circ} \mathrm{C}$ on glass beads. Working culture of bacteria was maintained on an agar slant at $4{ }^{\circ} \mathrm{C}$ and subcultured in Luria-Bertani (LB) broth (10 g tryptone, $5 \mathrm{~g}$ yeast extract, $5 \mathrm{~g} \mathrm{NaCl}$ per liter) prior to 
use. The bacterial culture maintained on agar slant at $4^{\circ}$ $\mathrm{C}$ was subcultured in Luria-Bertani (LB) broth (10 g tryptone, 5 g yeast extract, $5 \mathrm{~g} \mathrm{NaCl}$ per liter) prior to use. Briefly, a single MRSA colony was inoculated into the LB broth and incubated for $24 \mathrm{~h}$ at $37^{\circ} \mathrm{C}$ with shaking $(280 \mathrm{rpm})$. An overnight broth culture was diluted with fresh medium to obtain a starting inoculum of about $5 \times 10^{6} \mathrm{CFU} / \mathrm{ml}$.

\section{Determination of the minimal inhibitory concentration}

The minimal inhibitory concentrations (MICs) of TRQ and antibiotics were determined by a standard broth microdilution method in sterile 96-well microplates [24]. Two-fold serial dilutions were made in LB broth over a range to give final concentrations of $16500-33 \mu \mathrm{g} / \mathrm{ml}$ for TRQ, and 20-0.039 $\mu \mathrm{g} / \mathrm{ml}$ for vancomycin and linezolid, respectively. One hundred microliters of bacterial suspension $\left(5 \times 10^{6} \mathrm{CFU} / \mathrm{ml}\right)$ was added to each well. Negative control comprised LB broth and tested sample while the positive control was LB broth and bacterial suspension only. The final volume of each well was $200 \mu$ l. The MICs of test samples were detected after $24 \mathrm{~h}$ incubation at $37^{\circ} \mathrm{C}$, following addition of $20 \mu \mathrm{l}$ of $2.5 \mathrm{mg} / \mathrm{ml}$ TTC and incubation for an additional $20 \mathrm{~min}$ at $37{ }^{\circ} \mathrm{C}$. Viable bacteria reduced the yellow dye to pink. MIC was defined as the lowest sample concentration that prevented this change and exhibited complete inhibition of microbial growth [25].

\section{Checkerboard assay}

The combined effect of TRQ with the vancomycin or linezolid was evaluated by checkerboard microdilution method from which the fractional inhibitory concentration index (FICI), the predictor of the type of interaction between compounds, was obtained [26]. The TRQ was diluted two-fold in vertical orientation, while the antibiotic was diluted two-fold in horizontal orientation in the 96-well microtiter plates using LB broth. The concentrations tested for every combination of TRQ-antibiotic were their respective MICs, followed by $1 / 2,1 / 4,1 / 8$, and $1 / 16$ of the MICs values, respectively. The final volume of each well was $100 \mu \mathrm{l}$ comprising $50 \mu \mathrm{l}$ of each tested sample dilution. Subsequently, $100 \mu \mathrm{l}$ of the bacterial suspension $\left(5 \times 10^{6} \mathrm{CFU} / \mathrm{ml}\right)$ was added to all wells. Negative controls were LB broth and the TRQ/antibiotic combination while positive controls were media and bacterial suspension. After $24 \mathrm{~h}$ incubation at $37{ }^{\circ} \mathrm{C}, 20 \mu \mathrm{l}$ of TTC $(2.5 \mathrm{mg} / \mathrm{ml})$ was added to each well and the plates were incubated again for 20 min. Wells containing the solution which turned pink comparable to that of the positive control were interpreted as positive for bacterial growth, while the wells containing colorless solutions were interpreted as negative for bacterial growth. The FICI for the combination with negative results were calculated as follows: $\mathrm{FICI}=$ FIC A + FIC B, where FIC A is the MIC of drug A in the combination/MIC of drug $\mathrm{A}$ alone, and FIC B is the $\mathrm{MIC}$ of drug $\mathrm{B}$ in the combination/MIC of drug B alone. The results were interpreted as synergy (FICI $\leq 0.5$ ), addition $(0.5<\mathrm{FICI} \leq 1)$, indifference $(1<\mathrm{FICI} \leq 2)$ or antagonism $($ FICI $>2)$ [27, 28]. The experiments were performed in triplicate and the median FICI values were used in the analysis.

\section{Time-kill curve assay}

The time-kill analysis was used to determine the growth of MRSA in the presence of TRQ, vancomycin and linezolid, used as monotherapies or in combinations, for $24 \mathrm{~h}$. Based on MIC and FICI value for each drug, the concentrations of vancomycin and linezolid were set to $1 / 2 \times$ MIC, while TRQ was assessed at $1 / 2 \times$ MIC and $1 / 8 \times$ MIC, respectively. Then, bacterial solution was added to each solution $\left(5 \times 10^{6} \mathrm{CFU} / \mathrm{ml}, 6 \mathrm{ml}\right)$, and incubated at $37{ }^{\circ} \mathrm{C}$ with shaking. The growth control flasks contained only bacteria and $6 \mathrm{ml} \mathrm{LB}$ broth. At predetermined time points $(0,2,4,6,8,10,12$ and $24 \mathrm{~h}), 10 \mu \mathrm{l}$ of the samples were taken aseptically for bacterial counts. Each aliquot was serially diluted, plated onto LB agar plates and incubated for $24 \mathrm{~h}$ at $37^{\circ} \mathrm{C}$ in order to determine the number of CFU $/ \mathrm{ml}$. The colonies were counted only on plates that had between 30 and 300 colonies. Subsequently, time-kill curves were generated by plotting the $\log 10 \mathrm{CFU} / \mathrm{ml}$ against the time (h). Concentrations of each tested sample with negative $24 \mathrm{~h}$-antibacterial effects were selected for synergistic studies. The time-kill assays on the TRQ/antibiotic combinations were performed in the same manner as described above. Time-kill curves were then constructed as a function of time and the results were interpreted by the effect of the combination in comparison with the most active single drug alone. The interaction was defined as the $\log 10 \mathrm{CFU} / \mathrm{ml}$ increase in killing at $24 \mathrm{~h}(\triangle \mathrm{LC} 24)$ as follows: $\triangle \mathrm{LC} 24 \geq 2 \log 10 \mathrm{CFU} / \mathrm{ml}$, synergy; $\Delta \mathrm{LC} 24=1-2 \log 10 \mathrm{CFU} / \mathrm{ml}$, additivity; $\Delta \mathrm{LC} 24= \pm 1$ $\log 10 \mathrm{CFU} / \mathrm{ml}$, indifference; and $\Delta \mathrm{LC} 24>-1 \log 10 \mathrm{CFU} /$ $\mathrm{ml}$, antagonism [29]. Bactericidal activity is defined as $\mathrm{a} \geq$ $3-\log$ reduction in the initial CFU count within $24 \mathrm{~h}$.

\section{Biofilm assay}

The preparation of a mature biofilm of MRSA was performed according to our previous work [23]. Briefly, the overnight culture of MRSA in LB medium supplemented with $0.25 \%$ glucose (LB-G) was diluted in the respective medium to an optical density at $600 \mathrm{~nm}$ (OD600) of 0.05 . Then, $200 \mu \mathrm{l}$ aliquots of bacterial solutions were placed into a 96-well microtiter plate, while the wells containing medium served as negative controls. After $24 \mathrm{~h}$ of incubation at $37{ }^{\circ} \mathrm{C}$, media and planktonic cells were removed and wells containing biofilms were rinsed 
with $200 \mu \mathrm{l}$ of $0.9 \% \mathrm{NaCl}$. Antibiotic agents diluted in LB-G medium at different concentrations, based on the result of checkerboard method, were tested as single drugs and in combinations by adding $200 \mu \mathrm{l}$ of the tested sample to each well. Wells containing medium only served as negative controls. Following $24 \mathrm{~h}$ incubation at $37{ }^{\circ} \mathrm{C}$, the wells were washed to remove planktonic cells and ensure that only cells within biofilms were assayed. Then the XTT reduction assay was performed to evaluate the viability of the biofilms. For this purpose, $40 \mu \mathrm{l}$ of the XTT-PMS solution $(200 \mathrm{mg} / \mathrm{ml}$ XTT, $2 \mu \mathrm{M}$ PMS) was added to each well, plates were incubated for $2 \mathrm{~h}$ at $37{ }^{\circ} \mathrm{C}$ in the dark and the optical density was then measured at $490 \mathrm{~nm}$ using a microplate reader. A decrease in the number of live cells correlates with a decrease in overall activity of the dehydrogenases responsible for transforming the sodium salt of tetrazolium XTT into formazan which was determined colorimetrically. All experiments were repeated three times.

\section{Statistical analysis}

All the experiments were performed in triplicate. Data were expressed as mean \pm standard deviation. Statistical analyses and significance, as measured by the Student's $t$-test for paired samples were performed using Prism software version 4.0 (GraphPad Software, CA, USA). In all comparisons, $p<0.05$ was considered statistically significant.

\section{Results}

\section{Antibacterial activities of TRQ and combined effect with vancomycin and linezolid on MRSA}

The antibacterial activity of TRQ, vancomycin and linezolid against MRSA was assessed using the broth microdilution method and the results are shown in Table 1. The MRSA strain was susceptible to TRQ formula with MIC value $4125 \mu \mathrm{g} / \mathrm{ml}$, while the MIC values for both tested antibiotics were $2.5 \mu \mathrm{g} / \mathrm{ml}$.

Table 1 also summarizes the results of microbial growth inhibition by the combination of TRQ and vancomycin and TRQ and linezolid, respectively, determined by the checkerboard method. As evident from the table, TRQ markedly enhanced the activities of the tested antibiotics by reducing their MICs. The MIC value for vancomycin was reduced from $2.5 \mu \mathrm{g} / \mathrm{ml}$ to $1.25 \mu \mathrm{g} / \mathrm{ml}$ when used in combination with TRQ. Likewise, a 2-fold MIC reduction was found for linezolid in the presence of TRQ. Reduction in MIC of TRQ in combination with antibiotics was also observed. When combined with vancomycin, the MIC of TRQ was reduced 2 -fold, while the combination with linezolid resulted in an 8-fold reduction of its MIC. According to the calculated FICI values (Table 1), the interactions of TRQ and vancomycin as well as of TRQ and linezolid were all classified as additive $(0.5<\mathrm{FICI} \leq 1.0)$.

\section{Time-kill curve analysis of TRQ, vancomycin and linezolid and their combinations against MRSA}

An evaluation of the dynamic relationship between TRQ and MRSA was performed by time-kill experiments and the results are shown in Fig. 1. At concentration $1 \times$ MIC, TRQ had strong growth inhibitory effects on MRSA. A large drop in colony counts observed during $12 \mathrm{~h}(>8 \log \mathrm{CFU} / \mathrm{ml})$ resulted in bacterial eradication within $24 \mathrm{~h}$. However, the ability of TRQ to inhibit microbial growth decreased with reducing its concentration. At concentration $1 / 2 \times \mathrm{MIC}$, TRQ showed inhibitory effect on the bacteria but was followed by bacterial regrowth after 6 to $24 \mathrm{~h}$ of incubation. TRQ at concentrations $1 / 4 \times \mathrm{MIC}$ and $1 / 8 \times \mathrm{MIC}$ showed a similar tendency as the control group.

The findings of time-kill studies for the planktonic MRSA strain during exposure to combination of TRQ and antibiotics are presented in Fig. 2. Figure 2a shows the effect of TRQ at concentration $1 / 2 \times$ MIC and vancomycin at concentration $1 / 2 \times \mathrm{MIC}$, used alone and in combination against MRSA. At the subinhibitory concentrations tested, the two antibacterial agents used alone showed little (TRQ) or no activity (vancomycin) on bacterial growth. However, combination of $1 / 2 \times \mathrm{MIC}$ vancomycin with $1 / 2 \times$ MIC TRQ induced a strong antibacterial effect leading to eradication of MRSA during $24 \mathrm{~h}$. The combination of TRQ/ vancomycin increased the killing effect by $9.32\left(\Delta \mathrm{LC} 24>2 \log _{10} \mathrm{CFU} / \mathrm{ml}\right)$ at $24 \mathrm{~h}$, compared with the most active single drug TRQ, which demonstrated that the TRQ had a synergistic

Table 1 Minimal inhibitory concentration (MIC) and fractional inhibitory concentration index (FICl) of Tanreqing, vancomycin and linezolid against MRSA

\begin{tabular}{|c|c|c|c|c|c|}
\hline \multirow[t]{2}{*}{ Strain } & \multirow[t]{2}{*}{ Agent } & \multicolumn{2}{|c|}{ Minimal inhibitory concentration $(\mu \mathrm{g} / \mathrm{ml})$} & \multirow[t]{2}{*}{$\mathrm{FICl}$} & \multirow[t]{2}{*}{ Outcom } \\
\hline & & Alone & Combination & & \\
\hline \multirow{2}{*}{$\begin{array}{l}\text { MRSA } \\
\text { ATCC } \\
43300\end{array}$} & $\begin{array}{l}\text { Tanreqing } \\
\text { Vancomycin }\end{array}$ & $\begin{array}{l}4125 \\
2.5\end{array}$ & $\begin{array}{l}2063 \\
1.25\end{array}$ & 1 & Addition \\
\hline & $\begin{array}{l}\text { Tanreqing } \\
\text { Linezolid }\end{array}$ & $\begin{array}{l}4125 \\
2.5\end{array}$ & $\begin{array}{l}516 \\
1.25\end{array}$ & 0.625 & Addition \\
\hline
\end{tabular}

Results are means of three different experiments. The results were interpreted as synergy $(\mathrm{FICl} \leq 0.5)$, addition $(0.5<\mathrm{FICl} \leq 1)$, indifference $(1<\mathrm{FICl} \leq 2)$ or antagonism ( $\mathrm{FICl}>2$ ) 


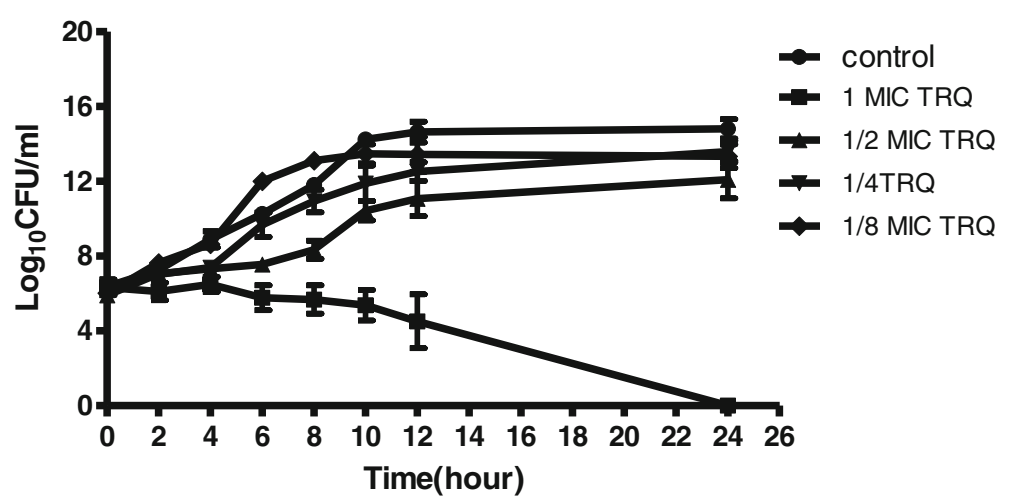

Fig. 1 Activity of TRQ at different concentrations in a time-kill analysis against MRSA

effect with vancomycin against MRSA. The time-kill curves of TRQ and linezolid alone and in combination are shown in Fig. 2b. Linezolid alone at concentration 1/ $2 \times$ MIC showed antibacterial effect from $0 \mathrm{~h}$ to $12 \mathrm{~h}$. However, after that the growth rate increased rapidly. In contrast, combination of TRQ at its $1 / 8 \times \mathrm{MIC}$ and linezolid $(1 / 2 \times$ MIC) greatly reduced the viable counts of bacteria during $24 \mathrm{~h}$ when compared with the most active agent used alone. The combination of TRQ with linezolid resulted in a potent synergistic effect on MRSA with $\triangle \mathrm{LC} 24=6.38$. Taken together, TRQ combined with conventional antibiotics at subinhibitory concentrations resulted in strong, long-lasting synergistic antibacterial effects. In addition, the two combinations reduced the viable count by $>3 \log _{10} \mathrm{CFU} / \mathrm{ml}$ when compared with the starting inoculum, demonstrating a bactericidal effect in this way.

Effect of TRQ alone and in combination with vancomycin and linezolid on MRSA biofilm

The antibiofilm effect of TRQ alone and in combination with antibiotics was studied against MRSA embedded in
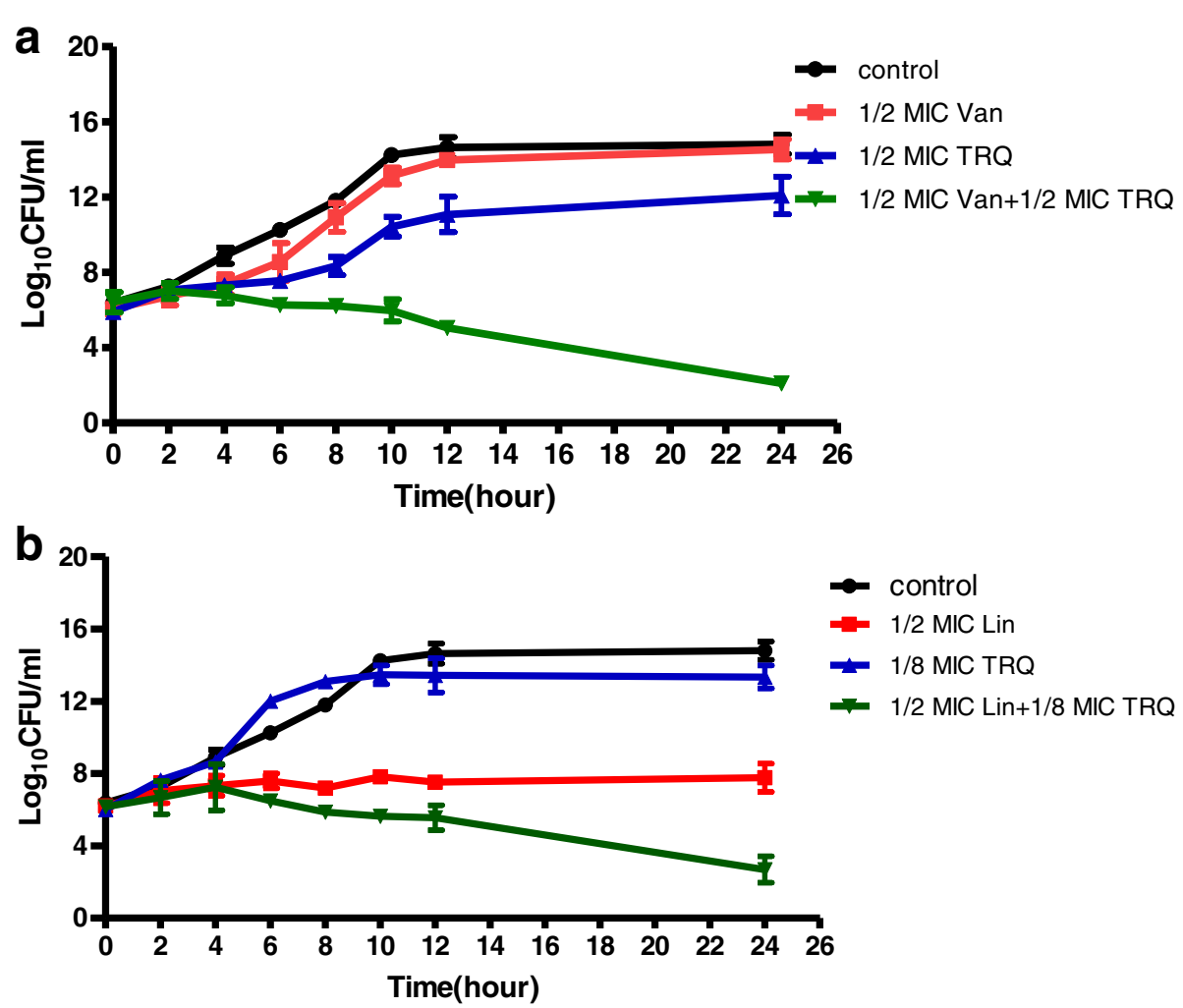

Fig. 2 Time-kill curves of TRQ, vancomycin and linezolid alone and in combinations against MRSA (A. TRQ with vancomycin; B. TRQ with linezolid) 
the mature biofilm by evaluating the metabolic activity of the biofilm cells and the results are presented in Figs. 3 and 4. As shown in Fig. 3, treatment with vancomycin alone at sub-MIC concentrations did not disrupt preformed biofilms and did not significantly induce biofilm cell death. In contrast, TRQ alone at concentrations $1 / 2 \times$ MIC or $1 / 4 \times$ MIC was able to cause a strong statistically significant reduction of the viability of bacteria in mature biofilms, compared to the untreated control biofilm. The combination of $1 / 2 \times$ MIC TRQ with $1 / 2 \times$ MIC or $1 / 4 \times$ MIC vancomycin resulted in a synergistic antibiofilm effect significantly higher than for each single agent ( $p<0.001$ and $p<0.01$, respectively).

Figure 4 displays the results of antibiofilm activity of TRQ alone and in combination with linezolid. When used at concentration $1 / 2 \times$ MIC, linezolid reduced the viability of mature MRSA biofilm, while at $1 / 4 \times$ and $1 /$ $8 \times$ MIC this antibiotic did not significantly affect the growth of biofilm, compared with untreated control biofilm. In contrast, TRQ at tested concentration $1 / 8 \times$ MIC showed strong activity against cells of the MRSA biofilm. A synergistic effect has been observed when subinhibitory concentrations of both TRQ $(1 / 8 \times \mathrm{MIC})$ and linezolid $(1 / 2-1 / 8 \times \mathrm{MIC})$ were combined together to treat mature MRSA biofilms $(p<0.001)$.

\section{Discussion}

Inappropriate antibiotics therapy and overuse of antibiotics together with the lack of novel, more effective drugs has greatly contributed to the emergence of multidrug-resistant bacteria. Chinese herbal drugs with a long tradition of use in therapy of infectious diseases may serve as sources of new antimicrobial agents or, in combination with conventional antibiotics, may complement conventional therapies and so offer a promising strategy to overcome bacterial resistance mechanisms and restore the effectiveness of antibiotics.
To our knowledge, this investigation for the first time reports the in vitro antimicrobial effect of the TRQ traditional formula against multidrug-resistant bacteria. MRSA was found to be sensitive to TRQ, although to a much lesser extent than to commonly used anti-MRSA antibiotics, vancomycine and linezolid. Our study showed that, in addition to its weak antibacterial effect against MRSA, TRQ also possess the potential to enhance the activity of vancomycine and linezolid against that serious pathogen. The effect of TRQ injection combined with antibiotics on planktonic MRSA was remarkably higher than that of single antibiotics.

The accurate prediction of synergy between a commercial antibiotic and a natural product, based upon the results of in vitro testing, is crucial for the determination of optimal doses of agents used in the combination antimicrobial therapy [30]. In this study we applied two most widely used methods, the checkerboard method and time-kill curve assay, to determine the interactions between TRQ and vancomycin or linezolid. The results of the checkerboard tests showed decrease in the MIC when combining TRQ with each of the tested antibiotics, which indicates the ability of TRQ to enhance the antibacterial activity of those antibiotics against MRSA due to additive interaction. The time-kill curves of vancomycin and linezolid revealed that both drugs were non-concentration dependent antibiotics, which coincides with previous reports [31, 32]. Most importantly, the resulting time-kill data revealed that TRQ can greatly increase the susceptibility of MRSA strain toward vancomycin and linezolid. At subinhibitory concentrations, TRQ was found to be able to synergistically increase the antibacterial activity of the tested antibiotics, ensuring their prolonged effectiveness. As evident, the time-kill studies demonstrated a higher degree of synergy, as did the checkerboard analysis. However, the results obtained in the comparative checkerboard and

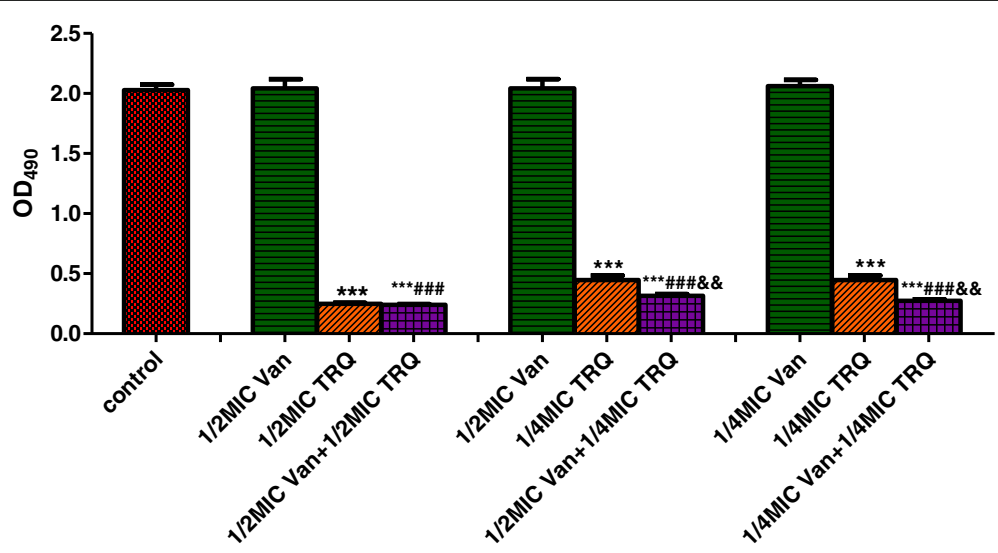

Fig. 3 Effect of TRQ combined with vancomycin on the preformed MRSA biofilm. Results are presented as the mean \pm standard deviation of triplicate assays. (*** $p<0.001$ vs. control group; \#\#\#p<0.001 vs. vancomycin group; \&\&p<0. 01 vs. TRQ group) 


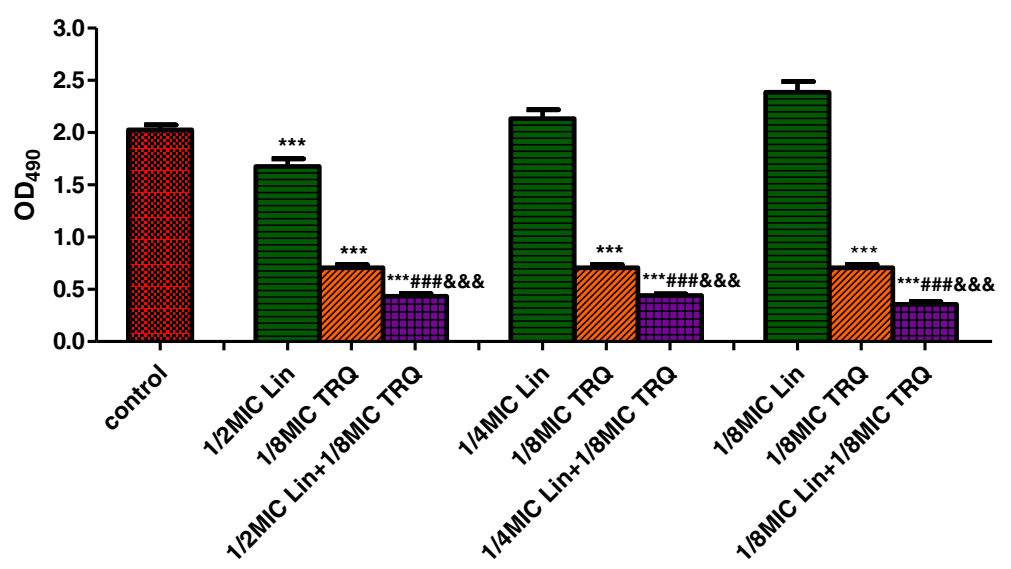

Fig. 4 Effect of TRQ combined with linezolid on the preformed MRSA biofilm. Results are presented as the mean \pm standard deviation of triplicate assays. ${ }^{* * *} p<0.001$ vs. control group; \#\#\#p $<0.001$ vs. linezolid group; $\& \& \& p<0.001$ vs. TRQ group)

time-kill studies have often been at odds because each method measures different parameters [33]. Although the checkerboard method is simple to perform, it is based upon MICs which reflect the inhibition of bacterial growth only. Since the results are usually examined only at one point in time, this method typically provides a static view of antimicrobial interaction, whereas the FIC indices calculation and interpretation incorrectly assume that all antimicrobials have linear dosage-response curves. On the other hand, the time-kill curve assay measures the microbicidal activity of a drug combination and, based on serial colony counts, provides a dynamic picture of antimicrobial action and interaction over time, giving more detailed data, including the rate and extent of antibacterial activity of drug combinations [34]. Although the experiments are labor-intensive and time-consuming, the time-kill method is considered as a more reliable predictor of in vivo synergy [33].

The ability of MRSA to form biofilms greatly contributes to its survival and virulence, thus limiting the possible therapeutic options. It is well-known that bacteria grown in biofilms differ greatly from the same organisms grown in suspensions by having different growth characteristics and taking up nutrients and drugs differently [35]. Therefore, besides activity against planktonic bacteria, in this study we have also evaluated the efficacy of combined TRQ/antibiotic therapy against MRSA embedded in biofilm. To quantify biofilm growth, metabolic activity within the biofilm was measured using XTT reduction assays, which are known to correlate with biofilm CFU [36]. The obtained results proved that subinhibitory concentrations of TRQ are very effective against mature MRSA biofilms, supporting the previous report on strong antibiofilm properties of TRQ [23]. Most importantly, we have found that TRQ can greatly increase antimicrobial susceptibility of bacteria grown in biofilms to conventional antibiotics.
While vancomycin or linezolid alone at subinhibitory concentrations did not significantly affect the growth of biofilms, their combination with this traditional Chinese drug which potently enhanced their antibiotic action against biofilms showed a great promise in dispersing existing MRSA biofilms.

TRQ injection is a multicomponent Chinese herbal drug rich in five active compounds, baicalin, ursodeoxycholic acid, chenodeoxycholic acid, chlorogenic acid and caffeic acid, which are considered important for its quality evaluation [12]. Interestingly, all of them are reported to possess a wide range of bioactivity, including antibacterial properties. As major constituents of Scutellariae baicalensis radix, a well-known TCM herbal drug used in the treatment of inflammation, cardiovascular diseases, bacterial and viral infections, baicalin and its aglycone baicalein have been studied extensively [37]. Baicalin or baicalein alone showed moderate antibacterial activity against resistant $S$. aureus strains with MIC values from 64 to $256 \mu \mathrm{g} / \mathrm{ml}$ [38-40]. Moreover, when used at concentrations lower than their MICs in combination with b-lactams, tetracycline, oxytetracycline and ciprofloxacin, both flavones showed remarkable synergies and greatly increased the susceptibility of MRSA to those antibiotics, demonstrating the ability to restore their effectiveness. The synergistic effect of baicalin/baicalein on MRSA may involve multiple mechanisms of action, such as inhibition of efflux pumps like NorA, which are able to efflux a range of antibiotics, or by interfering with the cell wall integrity through direct binding to peptidoglycan structure [39, 41-43]. Baicalein may also act as an inhibitor of bacterial resistant related enzymes such as penicillinase, associated with penicillin resistance in penicillinase-producing MRSA [44]. Furthermore, baicalein was shown to inhibit the MRSA pyruvate kinase, an enzyme essential for S. aureus growth and survival, as well as to reduce the activity 
of virulence factors produced by $S$. aureus, such as $\alpha$-hemolysin which might contribute to its antibacterial actions [45]. Recently, Chen et al. reported that baicalein possesses anti-biofilm properties, demonstrating its ability to inhibit $S$. aureus biofilm formation, disrupt the already formed biofilms and enhance vancomycin permeability, reduce the production of staphylococcal enterotoxin $\mathrm{A}$ and $\alpha$-hemolysin, and inhibit the quorum sensing system [46]. Chlorogenic and caffeic acids are phenolic acids which were found to be effective against both Gram-negative and Gram-positive bacteria, including $S$. aureus, showing antistaphylococcal properties on both planktonic and biofilm cells. They have been shown to exert their antibacterial action by disrupting membrane function through increased cell membrane permeability, depolarized cell membranes, and reduced respiratory activity, which can lead to cell death $[47,48]$. It is important to highlight that subinhibitory concentrations of those phenolic acids attenuate virulence and hamper $S$. aureus infections through inhibition of different secreted and/or cell wall-related virulence factors [48-50]. Lima et al. [51] reported that caffeic acid potentiated the antibiotic activity of norfloxacin, imipenem and gentamicin against Staphylococcus aureus, Escherichia coli and Pseudomonas aeruginosa strains. Besides polyphenolic constituents of $\mathrm{TRQ}$, bile acids originating from animal drugs are also reported to possess antibacterial activity $[52,53]$. However, it is also worth to mention that some pharmacologically active compounds used today in the treatment of non-infectious conditions are having antimicrobial activities and are acting in different manners on microbial growth. Known as non-antibiotics, several anti-inflammatory, neurotropic, diuretic, antispasmodic and mucolytic agents might themselves be effective and/or potentiate the efficacy of certain conventional antibiotics [54-56]. Therefore, it has to be bear in mind the co-administration of antibiotics and plant-derived non-antibiotics could also contribute to reducing resistance and enhancing drug activity.

The use of traditional Chinese herbal drugs in the treatment of infectious diseases may have some advantage due to their quite different mechanism of activity from the antibiotics. Chinese herbal formulas used for treating infections usually exhibit anti-inflammatory activity in addition to their antimicrobial effects. Herbal drugs classified in TCM as heat-clearing and detoxifying, such as Scutellariae radix, Coptidis rhizoma, Lonicerae flos, Forsythiae fructus etc., are common constituents of the preparations of this type. Modern pharmacological studies revealed that they can exert anti-inflammatory effect through different mechanisms of action, including inhibition of inflammatory cytokines and mediators, blocking of inflammatory signaling, and interfering with chemokines. At the same time, they are acting as antimicrobials through inhibition of microbial adherence to mucosal or epithelial surfaces, inhibition of endotoxin shock, and selective inhibition of microbial growth [57]. Additionally, the antipyretic properties of TRQ formula have been also reported [58]. Therefore, a novel approach to the treatment of MRSA infections based on the combination of existing antibiotics with traditional herbal drugs displaying multiple mechanisms of action, such as TRQ, may provide enhanced clinical benefits and be helpful in tackling antimicrobial resistance.

\section{Conclusions}

In summary, our findings revealed that TRQ in combination with vancomycin or linezolid has synergistic antibacterial effects against MRSA in planktonic form and biofilms, making the antibiotics more effective and extending their antibacterial action. Due to its ability to potentiate the effects of current antibiotics, this study supports TRQ as an effective treatment strategy for MRSA-associated infections.

\section{Abbreviations \\ ATCC: American type culture collection; FICl: Fractional inhibitory concentration index; LB: Luria-Bertani; MICs: Minimum inhibitory concentrations; MRSA: Methicillin-resistant Staphylococcus aureus; PMS: Phenazine methosulfate; TCM: Traditional Chinese medicine; TRQ: Tanreqing injection; TTC: 2,3,5-triphenyltetrazolium chloride; XTT: 2,3-bis-(2-methoxy-4-nitro-5-sulfophenyl)-2 h-tetrazolium-5-carboxanilide}

Funding

This work was supported by the National Natural Sciences Foundation of China (grant no. 81373884), Basic Scientific Research Fund from Ministry of Finance of China (grant no. Y201701, ZZ0808011, ZZ2014004), National Natural Sciences Foundation of Beijing (grant no.7132157) as well as Bilateral Cooperation Project Croatia-China financed by Ministry of Science \& Technology of the People's Republic of China and Ministry of Science and Education of the Republic of Croatia (grant no. 7-10)

\section{Availability of data and materials}

The datasets analyzed during the current study are available from the corresponding author on reasonable request.

\section{Authors' contributions}

WFY and $J \mathrm{~J}$ contributed equally to this work and should be considered co-first authors. Conceived and designed the experiments: YW, BB and SVK; Performed the experiments: WFY, JLL, YNS, SHM, CYR, CHL, YJX and GJT. Analyzed the data: BB, SVK, JLL and WFY; Wrote the manuscript: WY, BB and SVK. All authors read and approved the final manuscript.

Ethics approval and consent to participate Not applicable.

\section{Competing interests}

The authors declare that they have no competing interests.

\section{Publisher's Note}

Springer Nature remains neutral with regard to jurisdictional claims in published maps and institutional affiliations.

\section{Author details}

${ }^{1}$ Experimental Research Center, China Academy of Chinese Medical Sciences, Nanxiao Road 16, Dongzhimen, Beijing 100700, People's Republic of China. ${ }^{2}$ Department of Pharmacognosy, Faculty of Pharmacy and Biochemistry, University of Zagreb, Marulićev trg 20, 10000 Zagreb, Croatia. ${ }^{3}$ ChuanYun Ren, Dongzhimen Hospital, Beijing University of Chinese Medicine, Haiyuncang alley 5, Dongcheng district, Beijing 100700, People's Republic of 
China. ${ }^{4}$ Public health bureau of Tiexi district, Haifeng Road 2118, Tiexi district, Siping 136000, People's Republic of China.

\section{Received: 9 November 2017 Accepted: 14 May 2018 Published online: 30 May 2018}

\section{References}

1. World Health Organization. Antimicrobial resistance: global report on surveillance 2014. Geneva: WHO; 2014.

2. Köck R, Becker K, Cookson B, van Gemert-Pijnen JE, Harbarth S, Kluytmans, et al. Methicillin-resistant Staphylococcus aureus (MRSA): burden of disease and control challenges in Europe. Euro Surveill. 2010;15(41):19688.

3. Hu FP, Zhu DM, Wang F, Jiang XF, XU YC, Zhang XJ, et al. 2014 CHINET surveillance of bacterial resistance in China. Chin J Infect Chemother. 2015;5:401-10.

4. Monaco M, de Araujo FP, Cruciani M, Coccia EM, Pantosti A. Worldwide epidemiology and antibiotic resistance of Staphylococcus aureus. In: Compans RW, Honjo T, et al., editors. Current topics in microbiology and immunology. Berlin, Heidelberg: Springer; 2016. p. 1-36.

5. Kollef MH. Limitations of vancomycin in the management of resistant staphylococcal infections. Clin Infect Dis. 2007:45(Suppl 3):191-5.

6. Howden BP, Davies JK, Johnson PDR, Stinear TP, Grayson ML. Reduced vancomycin susceptibility in Staphylococcus aureus, including vancomycinintermediate and heterogeneous vancomycin-intermediate strains: resistance mechanisms, laboratory detection, and clinical implications. Clin Microbiol Rev. 2010:23:99-139.

7. van Hal SJ, Lodise TP, Paterson DL. The clinical significance of vancomycin minimum inhibitory concentration in Staphylococcus aureus infections: a systematic review and meta-analysis. Clin Infect Dis. 2012;54:755-71.

8. Elyasi S, Khalili H, Dashti-Khavidaki S, Mohammadpour A. Vancomycininduced nephrotoxicity: mechanism, incidence, risk factors and special populations. A literature review. Eur J Clin Pharmacol. 2012;68:1243-55.

9. Micek ST. Alternatives to vancomycin for the treatment of methicillinresistant Staphylococcus aureus infections. Clin Infect Dis. 2007;45:S184-90.

10. Flower A, Wang L-Q, Lewith G, Liu JP, Li Q. Chinese herbal medicine for treating recurrent urinary tract infections in women. Cochrane Database Syst Rev. 2015:CD010446.

11. Tong X, Li A, Zhang Z, Duan J, Chen X, Hua C, et al. TCM treatment of infectious atypical pneumonia-a report of 16 cases. J Tradit Chin Med. 2004; 24:266-9.

12. Sun L, Wei H, Zhang F, Gao S, Zeng Q, Lu W, et al. Qualitative analysis and quality control of traditional Chinese medicine preparation Tanreqing injection by LC-TOF/MS and HPLC-DAD-ELSD. Anal Methods. 2013:5:6431-40

13. Liu W, Jiang H, Cai L, Yan M, Dong S, Mao B. Tanreqing injection attenuates lipopolysaccharide-induced airway inflammation through MAPK/NFkB signaling pathways in rats model. Evid Based Complement Alternat Med. 2016;ID 5292346. https://doi.org/10.1155/2016/5292346.

14. Miao X, Zhou J, Li J, Liao Y, Zheng Y. Chinese medicine in inhalation therapy: a review of clinical application and formulation development. Curr Pharm Des. 2015;21(27):3917-31.

15. Liu SY, Zhang XL, Zhang ZH, Yi Y, Zhang J, Liu L, Liu XD. Effects of Tanreqing injection in various formula compatibilities on pharmacokinetics of main components. Chin Tradit Her Drugs. 2013:44(21):3030-4.

16. Zhang F, Sun L, Gao SH, Chen WS, Chai YF. LC-MS/MS analysis and pharmacokinetic study on five bioactive constituents of Tanreqing injection in rats. Chin J Nat Med. 2016;14(10):769-75.

17. Li C, Liu S, Luo G, Wang G, Zhang B, Nie Q. Comparison of plasma pharmacokinetics of Tanreqing solution between intratracheal aerosolization and intravenous injection in rats. Biomed Chromatogr. 2018; 32(3) https://doi.org/10.1002/bmc.4116.

18. He S, Wen $X, X u$ N. Clinical research of Tanreqing joint azithromycin sequential therapy in children with mycoplasma pneumoniae pneumonia. China Med Her.2009;6(35):49-50

19. Jiang HL, Mao B, Zhong YQ, Yang HM, Fu JJ. Tanreqing injection for community-acquired pneumonia: a systematic review of randomized evidence. Zhong Xi Yi Jie He Xue Bao. 2009;7(1):9-19.

20. Guo WP, Wang XL. Tanreqing injection for acute respiratory infection: clinical observation of 180 cases. Evaluat Anal Drug Use Hospit China. 2008;8(3):218-19.
21. Gao XQ, Gao JZ. Efficacy of Tanreqing injection combined with vancomycin for the treatment of MRSA infective pneumonia. China Pharm. 2011;16:1476-7.

22. Song ZX, Li LK, Li XG. Herbal Tanreqing-injection treating MRSA pneumonia: a clinical research. Chin J Nosocomial. 2010;20(11):1596-98.

23. Wang $Y$, Wang $T$, Hu J, Ren $C$, Lei $H$, Hou Y, et al. Anti-biofilm activity of TanReQing, a traditional Chinese medicine used for the treatment of acute pneumonia. J Ethnopharmacol. 2011;134:165-70.

24. National committee for clinical laboratory standards (NCCLS). Methods for dilution antimicrobial susceptibility tests for bacteria that grow aerobically fifth edition: approved standard M7-A5. Wayne: NCCLS; 2000.

25. Fankam AG, Kuete V, Voukeng IK, Kuiate JR, Pages J-M. Antibacterial activities of selected Cameroonian spices and their synergistic effects with antibiotics against multidrug-resistant phenotypes. BMC Complement Altern Med. 2011;11:104.

26. Basri DF, Sandra V. Synergistic interaction of methanol extract from Canarium odontophyllum Miq. Leaf in combination with oxacillin against methicillin-resistant Staphylococcus aureus (MRSA) ATCC 33591. Int J Microbiol. 2016:ID 5249534. https://doi.org/10.1155/2016/5249534

27. $\mathrm{Yu}$ H-H, Kim K-J, Cha J-D, Kim H-K, Lee Y-E, Choi N-Y, et al. Antimicrobial activity of berberine alone and in combination with ampicillin or oxacillin against methicillin-resistant Staphylococcus aureus. J Med Food. 2005;8:454-61.

28. Chan BCL, Ip M, Lau CBS, Lui SL, Jolivalt C, Ganem-Elbaz C, et al. Synergistic effects of baicalein with ciprofloxacin against NorA over-expressed methicillin-resistant Staphylococcus aureus (MRSA) and inhibition of MRSA pyruvate kinase. J Ethnopharmacol. 2011;137:767-73.

29. Chin JN, Jones RN, Sader HS, Savage PB, Rybak MJ. Potential synergy activity of the novel ceragenin, CAS-13, against clinical isolates of Pseudomonas aeruginosa, including multidrug-resistant $P$. aeruginosa. J Antimicrob Chemother. 2008;61:365-70.

30. Hemaiswarya S, Kruthiventi AK, Doble M. Synergism between natural products and antibiotics against infectious diseases. Phytomedicine. 2008; 15(8):639-52.

31. Rybak MJ. The pharmacokinetic and pharmacodynamic properties of vancomycin. Clin Infect Dis. 2006:42(Suppl 1):S35-9.

32. Zhou JJ, Liang BB, Wang R, Zhu XG, Song XJ, Cai Y, Bai N, Lin DF, Jiang ZW, Dong SY. In vitro antibacterial activity of linezolid and vancomycin against methicillin-resistant Staphylococcus aureus. Chin J Clin Pharmacol. 2010;26(8):593-6.

33. White RL, Burgess DS, Manduru M, Bosso JA. Comparison of three different in vitro methods of detecting synergy: time-kill, checkerboard, and $\mathrm{E}$ test. Antimicrob Agents Chemother. 1996;40:1914-8.

34. Pillai SK, Moellering RC, Eliopoulos GM. Antimicrobial combinations. In: Lorian V, editor. Antibiotics in laboratory medicine. 5th ed. Philadelphia: Lippincott Williams \& Wilkins; 2005. p. 365-438.

35. El-Azizi M, Rao S, Kanchanapoom T, Khardori N. In vitro activity of vancomycin, quinupristin/dalfopristin, and linezolid against intact and disrupted biofilms of staphylococci. Ann Clin Microbiol Antimicrob. 2005:4:2

36. Robertson EJ, Wolf JM, Casadevall A. EDTA inhibits biofilm formation, extracellular vesicular secretion, and shedding of the capsular polysaccharide glucuronoxylomannan by Cryptococcus neoformans. Appl Environ Microbiol. 2012;78(22):7977-84.

37. Zhao Q, Chen X-Y, Martin C. Scutellaria baicalensis, the golden herb from the garden of Chinese medicinal plants. Sci Bull. 2016;61(18):1391-8.

38. Liu IX, Durham DG, Richards RM. Baicalin synergy with beta-lactam antibiotics against methicillin-resistant Staphylococcus aureus and other beta-lactam-resistant strains of S. aureus. J Pharm Pharmacol. 2000;52:361-6.

39. Chan BC, Ip M, Lau CB, Lui SL, Jolivalt C, Ganem-Elbaz C, Litaudon M, Reiner $N E$, Gong H, See RH, Fung KP, Leung PC. Synergistic effects of baicalein with ciprofloxacin against NorA over-expressed methicillin-resistant Staphylococcus aureus (MRSA) and inhibition of MRSA pyruvate kinase. J Ethnopharmacol. 2011;137(1):767-73.

40. Lee YS, Jung EK, Cha JD. Synergistic effect between baicalein and antibiotics against clinic methicillin and vancomycin-resistant Staphylococcus aureus. Chemo Open Access. 2015:4:1-11.

41. Fujita M, Shiota S, Kuroda T, Hatano T, Yoshida T, Mizushima T, et al. Remarkable synergies between baicalein and tetracycline, and baicalein and beta-lactams against methicillin-resistant Staphylococcus aureus. Microbiol Immunol. 2005:49:391-6.

42. Novy P, Urban J, Leuner O, Vadlejch J, Kokoska L. In vitro synergistic effects of baicalin with oxytetracycline and tetracycline against Staphylococcus aureus. J Antimicrob Chemother. 2011;66(6):1298-300. 
43. Ayaz M, Subhan F, Sadiq A, Ullah F, Ahmed J, Sewell RD. Cellular efflux transporters and the potential role of natural products in combating efflux mediated drug resistance. Front Biosci (Landmark Ed). 2017;22:732-56.

44. Qian M, Tang S, Wu C, Wang Y, He T, Chen T, Xiao X. Synergy between baicalein and penicillins against penicillinase-producing Staphylococcus aureus. Int J Med Microbiol. 2015;305(6):501-4.

45. Qiu J, Niu X, Dong J, Wang D, Wang J, Li H, Luo M, Li S, Feng H, Deng X. Baicalin protects mice from Staphylococcus aureus pneumonia via inhibition of the cytolytic activity of a-hemolysin. J Infect Dis. 2012;206(2):292-301.

46. Chen Y, Liu T, Wang K, Hou C, Cai S, Huang Y, Du Z, Huang H, Kong J, Chen Y. Baicalein inhibits Staphylococcus aureus biofilm formation and the quorum sensing system in vitro. PLoS One. 2016;11(4):e0153468.

47. Lou Z, Wang H, Zhu S, Ma C, Wang Z. Antibacterial activity and mechanism of action of chlorogenic acid. J Food Sci. 2011;76(6):M398-403.

48. Luís Â, Silva F, Sousa S, Duarte AP, Domingues F. Antistaphylococcal and biofilm inhibitory activities of gallic, caffeic, and chlorogenic acids. Biofouling. 2014;30(1):69-79.

49. Li G, Qiao M, Guo Y, Wang X, Xu Y, Xia X. Effect of subinhibitory concentrations of chlorogenic acid on reducing the virulence factor production by Staphylococcus aureus. Foodborne Pathog Dis. 2014;11(9):677-83.

50. Wang L, Bi C, Cai H, Liu B, Zhong X, Deng X, Wang T, Xiang H, Niu X, Wang D. The therapeutic effect of chlorogenic acid against Staphylococcus aureus infection through sortase a inhibition. Front Microbiol. 2015;6:1031.

51. Lima VN, Oliveira-Tintino CD, Santos ES, Morais LP, Tintino SR, Freitas TS, Geraldo YS, Pereira RL, Cruz RP, Menezes IR, Coutinho HD. Antimicrobial and enhancement of the antibiotic activity by phenolic compounds: Gallic acid, caffeic acid and pyrogallol. Microb Pathog. 2016;99:56-61.

52. Itoh M, Wada K, Tan S, Kitano Y, Kai J, Makino I. Antibacterial action of bile acids against Helicobacter pylori and changes in its ultrastructural morphology: effect of unconjugated dihydroxy bile acid. J Gastroenterol. 1999;34(5):571-6.

53. Kong W, Wang J, Xing X, Jin C, Xiao X, Zhao Y, Zhang P, Zang Q, Li Z. Screening for novel antibacterial agents based on the activities of compounds on metabolism of Escherichia coli: a microcalorimetric study. J Hazard Mater. 2011;185(1):346-52

54. Tyski S. Non-antibiotics-drugs with additional antimicrobial activity. Acta Pol Pharm. 2003;60(5):401-4.

55. Wang WH, Wong WM, Dailidiene D, Berg DE, Gu Q, Lai KC, Lam SK, Wong BC. Aspirin inhibits the growth of Helicobacter pylori and enhances its susceptibility to antimicrobial agents. Gut. 2003;2:490-5.

56. Ayaz M, Subhan F, Ahmed J, Khan AU, Ullah F, Ullah I, Ali G, Syed NI, Hussain $\mathrm{S}$. Sertraline enhances the activity of antimicrobial agents against pathogens of clinical relevance. J Biol Res (Thessalon). 2015;22(1):4.

57. Muluye RA, Bian Y, Alemu PN. Anti-inflammatory and antimicrobial effects of heat-clearing chinese herbs: a current review. J Tradit Complement Med. 2014:4:93-8

58. Liu SY, Zhang XL, Zhang ZH, Yi Y, Zhang J, Liu L, Liu XD. Pharmacokinetics of main active ingredients of Tanreging injection in rats with LPS induced fever and its antifebrile effects. Central South Pharmacy. 2013;11(12):881-4.

\section{Ready to submit your research? Choose BMC and benefit from:}

- fast, convenient online submission

- thorough peer review by experienced researchers in your field

- rapid publication on acceptance

- support for research data, including large and complex data types

- gold Open Access which fosters wider collaboration and increased citations - maximum visibility for your research: over $100 \mathrm{M}$ website views per year

At BMC, research is always in progress.

Learn more biomedcentral.com/submissions 